\title{
The direct-to-consumer market for stem cell-based interventions in Australia: exploring the experiences of patients
}

\author{
Catherine Waldby*,1, Tereza Hendl ${ }^{2}$, lan Kerridge ${ }^{3}$, Wendy Lipworth ${ }^{3}$, Tamra Lysaght ${ }^{4}$ (i) \\ Megan Munsie 5,6 \& Cameron Stewart ${ }^{7}$ \\ ${ }^{1}$ Research School of Social Sciences, College of Arts \& Social Sciences, The Australian National University, Canberra, Australia \\ ${ }^{2}$ Institute of Ethics, History \& Theory of Medicine, Ludwig Maximilians University, Munich, Germany \\ ${ }^{3}$ Sydney Health Ethics, Faculty of Medicine \& Health, The University of Sydney, Sydney, Australia \\ ${ }^{4}$ Centre for Biomedical Ethics, Yong Loo Lin School of Medicine, National University of Singapore, Singapore \\ ${ }^{5}$ Centre for Stem Cell Systems, Faculty of Medicine, Dentistry \& Health Sciences, The University of Melbourne, Melbourne, Australia \\ ${ }^{6}$ Stem Cells Australia, Melbourne, Australia \\ ${ }^{7}$ Sydney Law School, University of Sydney, Sydney, Australia \\ *Author for correspondence: catherine.waldby@anu.edu.au
}

The prevalence of businesses selling autologous stem cell-based interventions to patients in Australia has raised serious concerns about how weaknesses in regulation have enabled the emergence of an industry that engages in aggressive marketing of unproven treatments to patients. Little is known about how patients experience this marketing and their subsequent interactions with practitioners. This paper reports results from 15 semistructured interviews with patients and carers, and also draws upon discussion conducted with patients, carers and family members (22 participants) in a workshop setting. We explore how Australian patients and carers understand and experience these interventions, and how their presumptions about the ethics of medical practice, and the regulatory environment in Australia have conditioned their preparedness to undergo unproven treatments.

First draft submitted: 16 July 2019; Accepted for publication: 17 December 2019; Published online: 3 February 2020

Keywords: adult stem cells • advertising • direct-to-consumer • ethical • legal/regulatory • marketing • policy

\section{Background}

Since the mid-2000s, scientists, medical professionals and regulators in Australia, Asia, Europe and North America have been concerned about the provision and direct-to-consumer (DTC) marketing of stem cell-based interventions [1-3]. Initially, concerns focused on patients with serious medical conditions - multiple sclerosis (MS), Parkinson's disease, motor neuron disease (MND) spinal cord injury - traveling overseas to low-to-middle income countries with weakly regulated medical infrastructure for procedures that lack demonstrated evidence of safety and efficacy, and in some cases may not contain stem cells $[4,5]$. More recently, domestic markets for interventions that use the patient's own cells have become established in high income countries as well, including the USA, Japan, Germany and Australia [4,6].

In Australia, the focus of this paper, approximately 70 privately owned clinics, mostly in metropolitan areas, currently provide patients with unproven autologous stem cell-based interventions (ASCBI). ASCBI refers to unproven procedures that use the patient's own harvested cells, usually fat, blood or bone marrow, to treat a range of conditions. Such interventions are offered primarily for the treatment of osteoarthritis (OA), but also for a wide range of other purposes ranging from facial rejuvenation and hair restoration, to serious medical conditions such as motor neurone disease, Parkinson's disease, autism and dementia [7]. There is a lack of clarity about what is actually administered to patients and none of the treatments are supported with high-level evidence. They carry uncommon but significant risks, associated with extracting, preparing and administering the cells, and none are reimbursed by public or private insurers. Patients pay significant sums out of pocket (AUD $\$ 6000$ to more than AUD $\$ 30,000$ ) for interventions that are, at best, supported with only weak levels of evidence [8]. Moreover, the industry markets

Future Medicine 
these interventions directly and aggressively to patients, in a manner that both exaggerates benefits and underplays risks $[7,9]$.

In this paper, we draw on data from interviews and two workshops with actual and prospective ASCBI patients and their carers, to examine their understandings of and experiences with this industry. As we will show, patients' assumptions and understandings often expose them to risk and direct harm, and make them vulnerable to the direct marketing used by clinics.

\section{Regulation \& regulatory exemptions in Australia}

Australia has a universal healthcare system characterized by values of patient care and equity, public health insurance (Medicare), free access to public hospitals and the sequestering of medical practice from frank marketization. These characteristics are articulated in the Health Insurance Act 1973, administrative laws governing public hospitals, and, variously, the Therapeutic Goods Act 1989, the Health Practitioner Regulation National Law 2009 (the National Law, 28), and the Australian Consumer Law, which sanction DTC advertising of medicines, set out the professional responsibility of doctors and mandate compliance with codes of conduct which protect patients from financial or other kinds of exploitation and from unsafe treatments.

Nevertheless, the stem cell industry was, until 2018, largely unfettered in Australia, primarily because regulators based their light touch approach on an assumption that autologous cell treatments are low risk. Clinics have been quick to develop business models which strategically exploited this approach. The Therapeutic Goods Administration (TGA) has oversight of supply, import, export, manufacturing and advertising of therapeutics including products derived from human cells and tissues. It takes a risk-based approach to regulation [10]. Since 2011, cellular material that is collected from a patient by a registered medical practitioner, manufactured and administered back to the same patient by the same practitioner, or under their supervision, is not considered a therapeutic good, and hence falls outside the TGA's purview. This exemption for autologous biologicals has meant that physicians have been able to freely offer ASCBI. It has also meant that unproven uses of autologous cells can proceed without being tested in clinical trials or meeting stringent manufacturing standards.

TGA regulations have recently been revised, in response to the rapid growth in stem cell clinics and as evidence of harm has emerged, including one death in Australia and a lengthening list of documented harms internationally [7,11]. After two rounds of public consultation, in 2015 and 2016 the TGA proposed a ban on DTC advertising of autologous cell and tissue products [12]. It also proposed to regulate, under the Biologicals Regulatory Framework, autologous cell and tissue products that are manufactured and used outside an accredited hospital, and that are more than minimally manipulated and/or for nonhomologous use (nonhomologous use refers to cases where the intended use requires the cells to perform a different basic function from their usual role in the tissue of origin). This framework came fully into effect in July 2019, while the ban on advertising came into effect in mid-2018 [8]. The efficacy of the new legislation will depend on its enforcement, however. Other regulatory bodies like the Australian Competition and Consumer Commission which regulates misleading advertising, or the Australian Health Practitioner Regulation Agency which is concerned with practitioner conduct, have exercised little active scrutiny of the sector.

\section{Literature review}

Although the literature commenting on these regulatory anomalies in Australia and internationally is now well developed [4,7,9,13-22], there is little empirical evidence of the way patients themselves, and their carers, understand and experience stem cell therapies and the expectations they have of their regulation. Almost all published fieldwork that directly engages patient perspectives and experience is focused on the matter of international travel to obtain $\mathrm{SC}$ interventions, and it is also concerned with a range of stem cell treatment types - embryonic, hematopoietic and foetal - as well as autologous. If we examine this literature, we see that early qualitative studies of stem cell tourism focus primarily on broad characterization of the patient groups and clinic destinations, often drawing on public data like blogs and Twitter feeds $[23,24]$. Some more recent studies provide richly textured accounts of the reasoning and experience of patients. Such studies report that patients are motivated by an absence of treatment options in their own nations, by a sense of dwindling time available to identify a treatment or cure, and by qualified optimism about their prospects in overseas clinics compared to what they sometimes regarded as deliberate obstruction from their domestic clinicians [25,26].

Only one comprehensive study of Australian stem cell tourism has been carried out [27-29]. Based on interviews with 24 patients and carers who had traveled overseas, and 46 clinicians and stem cell scientists and patients who 
had contemplated traveling abroad but elected not to pursue, the study found that patients traveled in order to maintain hope in some degree of improvement for their condition. Patients are neither driven by wild optimism nor by an absence of understandings of possible risks, but by the desire to have some agency in a situation where they and their carers feel they cannot change the trajectory toward deterioration and disability, or indeed death, if they remain within regulated national space. The desire for agency and a sense of autonomy, and to act as a scientific pioneer is also highlighted in two studies that focus on Chinese destinations [30,31]. Each of these studies identify a strong 'right to try' ethic among patients, a sense of both entitlement to access new treatments and a sense of impatience with regulatory systems that prevented access. They felt an ethical imperative and ethical obligation to take control of their own healthcare decision making, and could only do that by traveling to what they regarded as innovative international clinics.

By contrast, there are no published, qualitative studies of patients who access their own domestic markets for ASCBIs that we could identify at time of writing, despite the rapid escalation of such treatments in the USA, Canada and Japan. Although there are important communalities between domestic and transnational patients accessing unproven ASCBI, which we will explore below, there are some signal differences, particularly around attitudes to biomedical and clinical regulation.

\section{Methods}

Data for this study were collected as part of the Australia Research Council funded project Regulating Autologous Stem Cell Therapies in Australia' from two workshops with patients, their carers and family members and interviews with patients and their carers. The study was approved by the Human Research Ethics Committee of the University of Sydney. Participants were recruited using an e-advertisement disseminated by grant partner organizations on their websites, via newsletters and emails. For the workshops, participants nominated themselves in response to the advertisement. For the interviews, the study recruited a purposive sample, that is, we selected participants based on the characteristics of the population seeking ASCBIs, and the objectives of the study. We sought a range of disease conditions, although some conditions, for example, MND were difficult to represent due to the seriousness of the disease. We also sought a range of views about ASCBIs, from highly favorable to highly critical. Recruitment was iterative, and the researchers actively discussed ways to balance a range of disease and ASCBI experiences.

Workshops were conducted in November 2016, one in Sydney and one in Melbourne. The workshops were attended by 22 participants ( 9 men and 13 women). Out of these participants, 16 were patients with conditions including OA and MS, one patient had an unspecified condition for which she needed a lung transplant, and another had a balance disorder. Only one patient disclosed that he had undergone an ASCBI. Six participants were family members accompanying the patients. Prior to the workshops, participants obtained a policy brief with a summary of the legal and clinical aspects of ASCBIs in Australia to provide a basis for further discussion. The workshops were designed to stimulate free debate and participants were not asked to come to an agreement or present any particular positions regarding autologous stem cells. The workshops were chaired by a professional facilitator, participants were asked about their views on autologous stem cells and patient access to these interventions. The workshops were not audio recorded; Investigators took notes documenting major views presented by workshop participants. Note that, in the absence of recorded data, we only draw on the workshop findings as background to the recorded interview data.

Interviews were conducted in early 2017. Out of the 15 interview participants, 10 were women and five were men, with an age range of 32-76 years. Fourteen participants were patients seeking treatment for themselves. Their conditions included predominantly OA and MS. Other conditions included a tear in knee meniscus, an unspecified spinal problem, and a balance disorder. Four had received ASCBI (three in Australia and one in the USA), one was about to undergo an intervention (in Australia) and nine had considered having an ASCBI. One interviewee was a carer for her husband who died of motor neurone disease shortly before the interview. Participants resided in the cities of Sydney, Melbourne and Brisbane, and in rural Victoria. Demographic data was collected, including health condition, gender, age and occupation. Three participants opted to not provide some elements of this information; three omitted their age, and two only provided gender and health condition.

Out of the 15 interviews, four were follow-up interviews and 11 were interviews with participants who did not attend a workshop. The interviews were semistructured, using a standardized questionnaire. All interviewees were asked the same questions, in the same sequence. Semistructured interviews allow the interviewee to respond to interview questions in an open-ended way and may lead to additional topics being covered. They are appropriate for interviews that deal with complex topics and when the researchers seek in depth information [32]. The interview 
format was determined by the interview participant, in order to accommodate their health needs and personal circumstances. They were given three different options (Skype, phone and face-to-face interview) and chose the one most suitable to them and their needs. Twelve were conducted via phone, two via Skype and one face-to-face. One interviewer conducted all the interviews. Participants were asked about their views on and experiences with autologous ASC interventions, their understandings of regulation, presumed benefits and harms involved, and ideal circumstances under which patients should have access to them. Interviews were recorded, transcribed and coded in NViVo. The coder used grounded theory, the comparative approach [33,34]. Grounded theory is a well validated, widely used method of inductive theory building that draws on in depth, qualitative data obtained through purposive sampling, to identify the ways research participants understand their social world. Interviewees are treated as co-constructors of the knowledge generated by research, and the interview is designed to elucidate patterns of discursive reasoning and understanding in depth. The concerns they express and the patterns of individual response across the different questions form the basis of analysis. Hence, the study coded data for the primary themes emphasized and explored by the patients. Coding was verified by the research team.

Data analysis was hence thematic and conducted by the authors.

\section{Results}

The data suggest that patients' consideration of and decision to undergo an ASCBI was shaped particularly by four factors: illness experience, disillusion with current medical practice, unrealistic expectations of autologous stem cells and trust in Australian healthcare regulation and clinicians. In what follows we trace this reasoning in detail.

\section{Illness experience}

Patients who took part in the study had conditions at different stages, with various levels of onset, severity and prognosis. Most participants described their symptoms in terms of discomfort and deteriorated health and some patients, particularly those with OA, spoke of experiencing pain. For example, a patient with OA described her illness experience as follows.

"And I guess as I'm aging, and I have OA in my knees, and I fell over at work and fractured my ankle at the end of last year, and now my ankle isn't very good, even after doing physio, rehab, and... Pilates, which I still do. I don't like taking medication, besides which, it only just masks symptoms. It doesn't actually improve the problem." (Interview 8 patient OA, female, mid-fifties, clinical professional).

Another patient with OA said in a workshop that she lived on pain medication and expressed concerns about the future development of her chronic condition. She stated that she would rather die than be immobile. For her, the expected worsening of their illness and experiences with debilitating symptoms were the reasons for seeking treatment with stem cells.

Finding cures was also an important issue for patients with MS. One explained that there were two ways of looking at a cure. First, as stopping the disease and second, as recovering functionality that had been lost. This patient had experienced a slowing in the progression of the illness but complained about the damage that MS has done to him:

\footnotetext{
"It's very annoying. I speak in this way, and I stop. Frequently. Just because things get stuck. And for me, that was never - that was not the case. ... people often said to me that I could talk under wet cement, and. . yeah, I could talk anywhere, and now I can't. And I'm not great in certain situations, with lots of people around, and I can't plan very well anymore, and I can't execute those plans, and all that sort of thing. It's affected me cognitively more than anything else, and that was kind of my bread and butter." (Interview 9, patient, MS, male, mid-fifties, professional).
}

For several patients, time played a significant factor in their illness experience. These were particularly patients at a later stage of their condition or at an early stage of a condition with a serious prognosis. Several patients spoke about 'running out of time,' to find a suitable therapy. One patient described the time concerns in the following way:

"You don't have much time. So I suppose it depends where you are along that spectrum, and how bad your disease is, and how desperate you are to try new things, no matter how well they've been tested." (Interview 3, patient, MS, female, mid-sixties, retired professional). 
However, a few participants did not share this concern, due to the early stage of their condition or access to effective medication. These patients saw their situation as fortunate. This included several patients with MS who felt that they were 'doing fine,' especially because they had access to the medication they needed. Nevertheless, these patients acknowledged the possibility that they might arrive at a difficult point at a later stage of their illness.

"I'm very well at the moment, I'm not looking for anything. I don't need it, I'm traveling very well, but if I was in a bad way, I'm damn sure I'd be out there, digging around to find out what other alternatives there might be." (Interview 3, patient, MS, female, mid-sixties, retired professional).

Some of these patients were keeping themselves updated on new developments with autologous stem cells, usually through the newsletters of patient advocacy organizations such as MS Research Australia.

\section{Dissatisfaction with standard medical practice}

Patients were particularly interested in autologous stem cells due to their disillusionment with current standard medical practice. The disillusionment had several aspects. First of all, some patients were concerned with the absence of standard therapies available for their condition. This problem was discussed by patients and a carer in the workshop with respect to MND, for which no standard medical therapy is currently available. Some participants viewed autologous ASCBIs as their only option. Here we can see a similar desire for agency, a desire to do something, evident in the experiences of patients who travel overseas described in the literature review.

Second, many patients wanted better therapies than those currently available to them in the Australian healthcare system. A patient with arthritis described her view of knee replacement:

"From what I gather, they last about ten to fifteen years, so that would mean at my age I'd probably need to have another one done, if I live over 65, and I'm very active, and I'd like to stay that way. And I don't know, it's very strange if I had a part of my body in me that wasn't actually me. So the possibility of not having to do that is really appealing." (Interview 11, patient, arthritis, female, early fifties, professional).

Patients especially desired less invasive solutions for their conditions than surgery. This was mentioned by several patients with OA, who were concerned about the health implications of knee or hip replacement and wished to avoid surgical interventions. One woman expected that she might need a lung transplant in the near future and said that she would prefer stem cell therapy. In most cases, and despite the wide use of liposuction in ASCBIs, patients assumed that having a transplant of their own stem cells would be less invasive than many standard medical treatments, an assumption we discuss in detail below.

Another patient complained about the long waiting lists for knee or hip replacements. She explored treatments for her knees and reported:

"I was told... that it was an 18 month to two years waiting list for knees. And you get people my age, getting older, and have knee problems, and they can't get any relief because - well, I've got a girlfriend who's been waiting for a least four or five years for a knee, because she has problems with her knee, and they keep telling her she's too young to have a knee replacement." (Interview 13, patient, tear in the meniscus, female, mid sixties, retired from a job in the education sector).

She reported that while she was consulting surgeons, she met a friend who had knee problems, yet was walking properly. When she asked her which treatment she had, the friend told her about stem cell 'therapy,' which she subsequently decided to try.

Overall, the absence of standard therapies, or a dislike or distrust of those available, was seen by many as a major reason to explore novel clinical procedures. For example, a patient with MS who did not find autologous ASCBIs exceptionally appealing noted:

"Well, they're not necessarily more attractive, but at the moment, nothing else is really working, so I think everything should be investigated." (Interview 3, patient, MS, female, mid-sixties, retired professional).

Patients also raised the issue of desperation. This issue was most emphasized by patients suffering from pain, which they perceived not only as a symptom of their condition but also as an effect of unsatisfactory standard medical treatment. One patient in chronic pain, when asked if unproven interventions ought to be offered to patients, said: 


\begin{abstract}
"No, I don't think totally unproven. No. Not at all. Unless you're totally desperate, and then I'd put my hand up! (laughs)... and I can imagine somebody... being treated with morphine year after year, if they were promised something in Moscow, I could understand them going to Moscow! (laughs) I wouldn't, but I could understand somebody being totally desperate and trying anything." (patient, back problem, male, mid-seventies, self-employed).
\end{abstract}

Some patients expressed concerns that the lack of access to standard care, or unpalatable standard care, combined with patients' illness and desperation might place patients in a vulnerable position. Both interviewees and workshop participants expressed concerns about these issues in the discussion.

We can see that these domestic patients share some of the drivers and concerns evident among patients who sought overseas ASCBIs: both groups feel compelled by a sense of dwindling time, narrowing options, and a desire for alternatives to what seems like an implacable, inflexible mainstream medical profession.

\title{
Autologous stem cells as safe \& beneficial therapy
}

Participants' interest in ASCBIs was shaped by a range of expectations about their perceived therapeutic effects. Some participants envisaged that procedures using their own stem cells would have significant healing powers. An interviewee argued that they were appealing because:

"...it's coming from your own body. And the fact that it regenerates... It's like wound healing. If you get the right stuff, the wound actually builds itself up and you heal." (Interview 8, patient, OA, female, mid-fifties, clinical professional).

An MS patient described the interventions as magical, albeit with a degree of irony, as she admitted she had no knowledge of how they worked.

"They seem to be able to rebuild or recreate something you've lost." (Interview 3, patient, MS, female, sixties retired professional).

Even the more wary patients, those that expressed concerns about ASCBIs and had not sought them out, tended to equate autologous cells with safety, and the less sceptical equated them with a range of benign powers, particularly the capacity to 'naturally' regenerate oneself. One patient interviewed, a medical professional who had an autologous ASCBI for his knee OA and reported positive results, gave a very clear account of the line of reasoning, equating autologous cells with a number of benign and productive qualities. Asked to compare ASCBI with other interventions he stated:

"[The] other option for $O A$ is a knee replacement, so that's... you're putting artificial materials into your knee. It'll never be the same. It'll never have the same function. . . so, autologous stem cell treatment is much more attractive than that. It's using your own body to regenerate itself. Putting stem cells from one area of your body into another area, and stimulating regeneration. So, you know. It's natural." (interview 12, patient, OA, male, early fifties, medical researcher).

Here, we can see that autologous cells are cast as less invasive, more natural, more effective and as self-regenerative, all in the same breath.

Several patients contemplating hip or knee replacements made similar equations - autologous cells would be less invasive, not 'foreign,' like prostheses, more natural:

"you're using your own body's cells... for me, that is quite compelling." (Interview 4, patient, OA, female, age and profession not supplied): "It's very strange if I had a part of my body in me that wasn't actually me." (Interview 11, patient, arthritis, female, early fifties, professional).

Some patients also framed the presumed easy nature of ASCBI in terms of time. Many of these patients envisioned that the intervention involved a one-off treatment, a quick fix. A patient with OA who wanted to avoid a knee replacement expected that stem cells would reduce convalescence:

"There's no down time. You don't have to spend time in hospital, you don't have to have physiotherapy because you've had a knee replacement. You just go in, you have the injection, then you get up and you walk out, and you just get on with it." (Interview 13, patient, tear in the meniscus, female, mid sixties, retired from a job in the education sector). 
On the other hand, a patient doubtful about the promise of autologous ASCBI shared her concerns about the lack of scientific evidence supporting their use:
"And I think it sounds so permanent, you know stem cell'. Changing my stems! (laughs) Changing my cells! What a great idea! I think theoretically it sounds fabulous, but I think that the attraction to this sort of therapy would definitely be by people who are very unwell, and grasping at something that could potentially help them, give them some sort of assistance, some sort of hope. Sometimes hope is just the greatest thing to have ... but it's a pity that there's nothing concrete out there." (Interview 10, patient, MS, female, early sixties, hospitality).

Another MS patient goes on to note that one of the potential risks of ASCBI is psychological harm related to false hope.

"[Patients are] putting their hopes on the line, and if it doesn't work or it gets worse, yeah, people can get depressed and it can affect their mental health." (Interview 5, patient, MS, female, early forties, stay at home mother).

Another concern raised by some participants related to financial harm, given the high cost of the interventions and the lack of evidence supporting their use.

"Vulnerable people might be wasting money on things that have no scientific evidence whatsoever." (Interview

1, patient, MS, female, early thirties, PhD student).

The general equation of ASCBI with safety, regeneration and beneficence derives from a number of sources. Patients received most information about these interventions from popular media, patient advocacy groups and from other patients, as well as the websites of the clinics themselves. Several patients mentioned that they have come across media stories framing ASCBI as the latest scientific development and a new promising therapy. Some of these stories involved celebrities who had received treatment and expressed satisfaction with their health results. In other words, patients were strongly influenced by an ecology of marketing information that reinforced their impressions of the innovative, safe and effective nature of ASCBI. We examine this ecology, and the ways that the TGA exemption facilitates it, in the discussion section of the paper.

\section{Trust in Australian Regulation \& Healthcare}

The majority of the patients had not considered the regulation of these interventions. At the time of the interviews, most patients were unaware that they were neither regulated nor medically proven.

"I understand that if it's being offered in Australia, it's passed some type of regulation. But I couldn't say anymore. My expectation is that you can't offer any medical service within Australia if there's not a government body that's approved that procedure." (Interview 14, patient, OA, male, mid-forties, manager).

More strikingly, this view was also shared by a patient who worked as a medical researcher at an Australian university. She actively explored ASCBIs for her condition, and stated that:

"My presumption is that the types of treatments that go on in hospitals have gone through a certain TGA or equivalent." (interview 1, patient, MS, female, early thirties, PhD student).

When told that ASCBIs were excluded from regulation, she said:

"I sort of feel that if I'm presenting myself to a doctor, that all the treatments that they provide are going to be regulated. So that would be my assumption, walking in the door. It surprises me that theyre not. . . That would seem to indicate to me that they [regulators] think there's somewhat of a lesser risk involved."

She was unconvinced that they were, in fact, lower risk, and had discontinued her pursuit of treatment.

It was clear in several of the interviews and in the workshop discussions that participants regarded good medical regulation as a specifically Australian quality. As one patient put it:

"Well, I'm intrigued at why, in Australia, which has just got so many regulations, they're not regulated." (interview 3, patient, MS, Female, mid-sixties, retired professional).

Another patient, who had undergone an ASCBI stated that: 
"I would never go overseas for a treatment: because I'd be really worried, and I wouldn't trust any doctor from overseas, or their regulations, but being in Australia, you think this will never, ever happen. You'd think this would never be allowed." (Interview 7, patient, balance disorder, male, mid-thirties, tradesman).

He had agreed to the procedure under the impression that he was receiving a well-regulated and proven form of treatment.

It was evident that patients' assessment of the risks for ASCBI was strongly influenced by the location of clinics in Australia, rather than in a dubious international destination. They assumed that they would get a higher standard of care than patients undergoing ASCBI abroad, particularly in developing countries. As one participant put it:

"if you go off to Russia to have that sort of stuff done, then you're in totally unregulated territory because you're outside of Australia." (interview 1, patient, MS, female, early thirties, PhD student).

A similar sense of safety, professional ethics and regulatory oversight was attributed to the Australian healthcare system more generally, and to the doctors who provided the ASCBIs. Many participants not only expected that interventions were regulated and approved, they also assumed that doctors were qualified to provide them and were genuinely well meaning and concerned with their patients' best interests.

"There would be certain regulations that... doctors can't be cowboys and ... that it's all done properly. I would like to know that whoever's performing the stem cell therapy or treatment, that they are reputable people." (Interview 4, patient, OA, female, age and profession not supplied).

The extent of trust in the Australian healthcare system was illustrated by the many patients who, even after they were informed that ASCBI were currently unregulated in Australia, continued to assumed that authorities, such as the Medical Board of Australia, guarantee that clinicians do not provide untested or potentially unsafe procedures to their patients:

"I've sort of - I suppose I trust our medical profession here, I trust our government to a reasonable degree. We're not a Third World country. . . We debate these things. I think we're very lucky to live in this country, and so I'm quite trusting of the safeguards that Australia puts in place." (Interview 3, patient, MS, female, mid-sixties, retired professional).

Some participants acknowledged the existence of 'bad' stem cell providers, for whom they used terms such as 'cowboys' or 'charlatans.' As one patient put it:

"[There are] unscrupulous physicians, I suppose, that are going to use autologous stem cell therapies for moneymaking, for profit, and not putting the patient first, and possibly doing procedures that's not their specialty, and hence, not evidence-based. So, that's the problem." (interview 12, patient, OA, male, early fifties, medical researcher).

He explained that these bad providers and 'incidents' that arose from the lack of TGA's oversight gave stem cell therapy a bad name. Nevertheless, he added, more stringent regulation would hinder research at a clinic with which he is affiliated, both as a patient and researcher. With more regulation, he claimed, the research would be "nowhere near... the stage that it's at. It would be backward."

Some participants implied that patients were responsible for identifying the 'good providers.' For example, one interviewee said that patients should be 'doing their own homework' and 'investigate reputable stem cell clinics.' In her view, "if you're not prepared to do background checks, don't bother" (Interview 4, patient, OA, female, no further demographic data). She said that the state should regulate 'pop-up clinics' but it was a person's choice whether they wanted to go forward with a procedure. Her view was that stem cell research and interventions were exciting innovations, and hence some degree of risk was to be expected.

Several patients also expressed views that suggested that they were inclined to trust stem cell providers over doctors providing standard therapy. In particular, they held the view that general practitioners and specialists do not want ASCBI to be promoted because they represent competition. As one patient clarified:

"[] stem cells dump them [orthopaedic surgeons] out of a job and out of money, because you don't have to go into hospital and stay there, and you don't have to have a big operation on your knee or whatever it is, and you just go in and have the injection and you get up and walk out." (Interview 13, patient, tear in the meniscus, female, mid sixties, retired from a job in the education sector). 
However, a few participants had serious concerns about the Australian healthcare system and its permissive approach to ASCBI. These included a nurse who has searched for evidence supporting the interventions but did not find any convincing data, and a participant who expressed a strong suspicion that clinicians look after their own interests rather than those of their patients. One participant told of a particularly pernicious experience, one that had left him with significant harm. The provider offered the patient a discount from AUD $\$ 12,000$ to AUD $\$ 3000$, while emphasising that he was 'doing him a favor.' The clinic did not disclose comprehensive risk and efficacy information to the patient during the consent-taking process and the patient agreed to the procedure under the impression that it was regulated, clinically proven and safe. His account is striking because, first, it makes clear that he was not afforded an opportunity for properly informed consent. Second, it encapsulates precisely the way clinics leverage patients' presumptions about the regulation of clinical practice and medical ethics in Australia.

"[The doctor] said, "Look, it fixes damage in your body. So if you've got damaged body parts, it will repair it."
So I'm thinking, well, no other doctor's got help for me at the moment. I've been to see all the specialists, and
this bloke's saying to me it's a hundred percent safe. Now, had he told me it wasn't a hundred percent safe and it
was experimental, there's no way in the world I would have done it, because I'm quite a cautious guy, so I'm not
going to go - that's why I consulted with him twice; because I was still in doubt that it was safe, but because he
kept saying it was safe, and he is a doctor, I just believed him. You know what I mean? And especially being in
Australia, I believed what he was saying to me." (Interview 7, patient, balance disorder, male, mid-thirties,
tradesman).

Several other patients noted that they did not receive any information about possible risks. They had simply been told that it should work. The majority of study participants held the view that patients need to be given full and transparent information about ASCBI, including whether they are proven or not. On being made aware of the unproven nature of treatments, several participants expressed concerns about the exploitative nature of such for-profit clinics. One patient noted the opportunity for providers to ramp up the number of interventions, each of which incurs a charge:

"It's suggested that each treatment will do the trick, but when people come into it more, it's then suggested to them that they might need four or five treatments, and each treatment seems to be in the region of $\$ 20,000$."

(Interview 2, patient, OA, female, age not provided, clinical professional).

When the issue of providers' conflict of interest was raised and discussed in workshops, many participants emphasized the need to protect vulnerable people, particularly because they invested trust in medical professionals. An interviewee stated succinctly:

"It [should] come under the umbrella of any and every procedure, and not be pulled out" and said, "Well, it's your cells, therefore it's your problem." (Interview 2, patient, OA, female, age not provided, clinical professional).

As participants assumed that autologous ASCBI were regulated, most of them also assumed that they were a proven therapy. As one patient who has undergone an [unproven] ASCBI in the USA put it:

"I felt reassured that there was a basis for it, there was a sound medical basis for it." (Interview 15, patient, back problem, male, mid-seventies, self-employed).

Only a handful of participants were aware of the absence of medical evidence for the safety and efficacy of autologous ASCBI for their particular conditions.

\section{Discussion}

We can see in the interviewees' accounts that they rely on a set of presumptions about the regulatory environment and protections, which they assume are intrinsic to the Australian healthcare system and health product market. They trusted in the efficacy and proven status of ASCBI, and as patients, they assumed they were protected from opportunistic medicine by a rigorous and uniformly applied national regulatory armature. The clinics' capacity to recruit patients prepared to undergo unproven treatments depended directly on these presumptions.

This trust led many patients to put possible concerns aside, and to consider or enter into interventions that several note they would never contemplate if they were offered in another country. Patients formed the intention to seek treatment in Australian stem cell clinics precisely because they were not overseas. Traveling to Russia or 
China or the Cayman Islands was regarded as dangerous, exploitative, and a destination for the desperate and vulnerable. ASCBI at home, on the other hand, were attributed with a high degree of safety, and the providers were attributed with expertise and empathy. These assumptions prevailed despite the fact that patients often described an opportunistic and poorly qualified element among clinical providers, who were prepared to neglect broader principles of informed consent in order to secure a paying customer. Under Australian law [35], and codified by the National Law and the Australian Medical Board guidelines [36], health practitioners have a duty of care to the patient to provide them with information about the material risks of having and not having an intervention, and to compare it with other available treatments. However, the patients' accounts suggest that Australian providers fail to observe this duty in most cases, and instead clinicians made unfounded claims about the safety and efficacy of the interventions. So, we can see that the stem cell industry leveraged the trust Australians have in health regulation, while at the same time operating in a space undisturbed by effective regulation.

The use of DTC websites meant that clinics could purvey their interventions as safe, proven, benign and natural, without the need for peer-reviewed research, clinical trials or any other mandated standard of clinical evidence. In our analysis of websites marketing ASCBI [37], we found that clinics were adept at using what Sipp et al. (2017) have termed 'tokens of legitimacy' [9]. These tokens give a veneer of scientific credibility to unsupported claims about the risks and benefits of ASCBI, including registrations of phantom clinical trials on unmoderated registration websites, membership of professional associations that are in fact industry advocates, and reference to unrecognized forms of medical expertise, for example, 'stem cell specialists.'

The power of such marketing is evident in the wide acceptance, among even the more critical study participants, of the qualifications of providers and of the ground-breaking nature of the interventions on offer. Prior to extended discussion in the workshops and interviews, participants were largely persuaded that ASCBI were more efficacious than other available treatments, or at minimum, would be worth considering as an alternative. The autologous nature of the interventions was pivotal here. In their accounts, patients considered autologous procedures as intrinsically safe. The cells' status as 'self' tissue was associated with a natural and minimally invasive treatment, and with easy recovery. Autologous tissue delivered by injection was favorably contrasted with donor tissues and medical devices, with risks of immune suppression and waiting lists, and with surgery: invasive, risky and involving long recover times.

More broadly, the portrayal of ASCBI on clinic websites and in other areas of mass and social media builds on popular associations of stem cells with self-regeneration and the miraculous reversal of ill-health [38]. The clinics could benefit from a broader ecology of information and popular understanding that predisposed patients and carers toward an optimistic view of ASCBI. In contrast, the study results suggest that expert information about the unregulated and unproven nature of these interventions was not easily available, even to well-educated professionals.

\section{Limitations of the study}

Our study findings are based on a small sample. While small numbers of in-depth interviews are appropriate for qualitative methods, this nevertheless may limit the degree of generalizability of the findings. The poor health of patients seeking ASCBI also limited the range of medical conditions experienced by our sample. The use of different technologies for interview (Skype, telephone, face to face) may have influenced interactions between interviewer and interviewee.

\section{Conclusion}

The TGA exemption of autologous cells and tissues from regulatory oversight opened up the way for opportunistic providers to colonize the public domain with unfounded claims and develop a lucrative market of paying patients. It is evident that health consumers need better access to reliable information about the relative risks and benefits of autologous ASCBIs. Currently, they have only access to passive information that is available on the websites of publicly funded institutions, such as Stem Cells Australia, and patient advocacy groups. To promote more informed decision making, dedicated funding is needed for support centers that patients can contact and receive information in a timely and responsive manner. Furthermore, ongoing review of the new TGA regulations is needed to ensure they actually address the conflicts of interest evident in the sector, and guard against the exploitation of new loopholes, such as the 'hospital use' exception to continue operating business as usual. Review is also needed for the process that are meant to protect consumers from exploitation; namely, the lodging and following of complaints made to the Australian Competition and Consumer Commission, the Medical Board of Australia and other professional governance agencies. 


\section{Executive summary}

- This study investigates the knowledge, understanding and experience of patients and prospective patients as they interact with the direct-to-consumer market for unproven stem cell-based interventions in Australia.

- It provides an account of the development of a poorly regulated autologous stem cell-based interventions (ASCBI) sector in Australia, and of recent attempts to improve regulation.

- The study is based primarily on interviews with 15 patients and carers, and also draws upon discussion conducted with patients, carers and family members (22 participants) in a workshop setting.

- The interviews identified four factors that led patients to consider or undertake an ASCBI: illness experience, disillusion with current medical practice, unrealistic expectations of autologous stem cells, and trust in Australian healthcare regulation and clinicians.

- The study finds that patients were not aware that ASCBIs were unproven treatments.

- It finds that patients reported a high degree of trust in the Australian regulatory environment, and assumed that the ASCBI clinics were properly regulated.

- It concludes that patients need better access to reliable information about the relative risks and benefits of autologous ASCBIs and ongoing review of the new Therapeutic Goods Administration regulations is needed to ensure they address the conflicts of interest evident in the sector.

\section{Financial \& competing interests disclosure}

This work was supported by an Australian Research Council grant (LP150100739). The authors have no other relevant affiliations or financial involvement with any organization or entity with a financial interest in or financial conflict with the subject matter or materials discussed in the manuscript apart from those disclosed.

No writing assistance was utilized in the production of this manuscript.

\section{Ethical conduct of research}

The authors have obtained approval for this project from the Human Research Ethics Committee at the University of Sydney. Consent has been obtained from the participants involved

\section{Data sharing statement}

Due to privacy concerns associated with detailed qualitative data collected from a small sample of individuals, this data is not being shared. Further information about access to data can be obtained by contacting the corresponding author.

\section{Open Access}

This work is licensed under the Attribution-NonCommercial-NoDerivatives 4.0 Unported License. To view a copy of this license, visit http://creativecommons.org/licenses/by-nc-nd/4.0/

\section{References}

1. Eliza B. Stem-cell experts raise concerns about medical tourism. Lancet 373(9667), 883-884 (2009).

2. Crozier G, Thomsen K. Stem cell tourism and the role of health professional organizations. AJOB 10(5), 36-38 (2010).

3. Brown C. Stem cell tourism poses risks. CMAJ 184(2), E121-E122 (2012).

4. Berger I, Ahmad A, Bansal A, Kapoor A, Sipp D, Rasko J. Global distribution of businesses marketing stem cell-based interventions. Cell Stem Cell 19(2), 158-162 (2016).

5. Regenberg A, Hutchinson L, Schanker B, Mathews DJ. Medicine on the fringe: stem cell-based interventions in advance of evidence. Stem Cells 27(9), 2312-2319 (2009).

6. Turner L. US clinics marketing unproven and unlicensed adipose-derived autologous stem cell interventions. Regen. Med. 10(4), 397-402 (2015).

7. Lysaght T, Lipworth W, Hendl T et al. The deadly business of an unregulated global stem cell industry. J. Med. Ethics 43, 744-746 (2017).

8. Therapeutic Goods Administration. Regulation of autologous cell and tissue products: Including so called 'autologous stem cell' therapies (2017). https://www.tga.gov.au/media-release/regulation-autologous-cell-and-tissue-products

9. Sipp D, Caulfield T, Kaye J et al. Marketing of unproven stem cell-based interventions: A call to action. Sci.Transl. Med. 9(397), eaag0426 (2017).

10. Trickett A, Wall D. Regulation of cellular therapy in Australia. Pathology 43(6), 627-634 (2011).

11. Bauer G, Elsallab M, Abou-El-Enein M. Concise review: a comprehensive analysis of reported adverse events in patients receiving unproven stem cell-based interventions. Stem Cells Transl. Med. 7(9), 676-685 (2018). 
12. Therapeutic Goods Administration. Consultation: regulation of autologous cell and tissue products and proposed consequential changes to the classification of biologicals (2016). www.tga.gov.au/sites/default/files/consultation-regulation-autologous-cell-and-tissue-products.pdf

13. Sipp D. Conditional approval: Japan lowers the bar for regenerative medicine products. Cell Stem Cell 16(4), 353-356 (2015).

14. Turner L, Knoepfler P. Selling stem cells in the USA: assessing the direct-to-consumer industry. Cell Stem Cell 19(2), 154-157 (2016).

15. Turner L. US stem cell clinics, patient safety, and the FDA. Trends Mol. Med. 21(5), 271-273 (2015).

16. Munsie M, Hyun I. A question of ethics: selling autologous stem cell therapies flaunts professional standards. Stem Cell Res. 13, 647-653 (2014).

17. Cohen C, Cohen P. International stem cell tourism and the need for effective regulation. Part I: stem cell tourism in Russia and India: clinical research, innovative treatment, or unproven hype? Kennedy Inst. Ethics J. 20(1), 27-49 (2010).

18. DeRenzo L. Stem cell tourism: the challenge and promise of international regulation of embryonic stem cell-based therapies. Case West. Reserve J. Int. Law 43(3), 877-918 (2011).

19. Devereaux M, Loring J. Growth of an industry: how U.S. scientists and clinicians have enabled stem cell tourism. AJOB 10(5), 45-46 (2010).

20. Lindvall O, Hyun I. Medical innovation versus stem cell tourism. Science 324(5935), 1664-1665 (2009).

21. Master Z, Resnik D. Stem-cell tourism and scientific responsibility. EMBO Rep. 12(10), 992-995 (2011).

22. McMahon D, Thorsteinsdóttir H. Regulations are needed for stem cell tourism: insights from China. AJOB 10(5), 34-36 (2010).

23. Ryan K, Sanders A, Wang D, Levine A. Tracking the rise of stem cell tourism. Regen. Med. 5(1), 27-33 (2009).

24. Levine A. Insights from patients' blogs and the need for systematic data on stem cell tourism. AJOB 10(5), 28-29 (2010).

25. Rachul C. "What have I got to lose?": an analysis of stem cell therapy patients' blogs. Health Law Review 20(1), 5-12 (2011).

26. Levine A, Wolf $\mathrm{L}$. The roles and responsibilities of physicians in patients' decisions about unproven stem cell therapies. J. Law Med. Ethics 40(1), 122-134 (2012).

27. Petersen A, Munsie M, Tanner C, MacGregor C, Brophy J. Stem Cell Tourism and the Political Economy of Hope. Palgrave McMillan, London, UK (2017).

28. Petersen A, Seear K. Technologies of hope: techniques of the online advertising of stem cell treatments. New Genet. Soc. 30(4), 329-346 (2011).

29. Petersen A, Seear K, Munsie M. Therapeutic journeys: the hopeful travails of stem cell tourists. Sociol. Health Illn. 36(5), 670-685 (2014).

30. Chen H, Gottweis H. Stem cell treatments in China: rethinking the patient role in the global bio-economy. Bioethics 27(4), 194-207 (2011).

31. Brophy J. Navigating the 'grey areas': Australian medical travelers in China’s stem cell bionetwork. Asia Pac. Viewp. 58(2), 216-227 (2017).

32. Cohen D, Crabtree B. Qualitative research guidelines project (2006). www.qualres.org/

33. Charmaz K. Constructing Grounded Theory. Sage, London, UK (2014).

34. Glaser B, Strauss A. The Discovery of Grounded Theory: Strategies for Qualitative Research. Sociology Press, CA, USA (1967).

35. Rogers v Whitaker [1992] HCA 58. 175 CLR 479, (19 November 1992) (1992). www.paci.com.au/downloads_public/court/12_Rogers_v_Whitaker.pdf

36. Medical Board of Australia. Good medical practice: a code of conduct for doctors in Australia (2014). www.medicalboard.gov.au/docu ments/default.aspx?record=WD14\%2f13332\&dbid=AP\&chksum=1GnSQD5LhB2UvesdywVfbw\%3d\%3d

37. Munsie M, Lysaght T, Hendl T, Tan HH, Kerridge I, Stewart C. Open for business: a comparative study of websites selling autologous stem cells in Australia and Japan. Regen. Med. 12(7), 777-790 (2017).

38. Haran J, Kitzinger J, McNeil M, O’Riordan K. Human Cloning in the Media: From Science Fiction to Science Practice. Routledge, Abingdon, UK (2008). 